\title{
In memoriam: Fumio Okano, innovator of 3D display
}

\author{
Jun Arai
}

Jun Arai, "In memoriam: Fumio Okano, innovator of 3D display," Proc. SPIE 9117, Three-Dimensional Imaging, Visualization, and Display 2014, $91170 \mathrm{~K}$ (5 June 2014); doi: 10.1117/12.2058117

Event: SPIE Sensing Technology + Applications, 2014, Baltimore, MD, United States 


\title{
In memoriam: Fumio Okano, innovator of 3D display
}

\author{
Jun Arai*a \\ ${ }^{a}$ Science and Technology Research Laboratories, NHK (Japan Broadcasting Corporation), \\ 1-10-11 Kinuta, Setagaya, Tokyo 1578510, JAPAN
}

\begin{abstract}
Dr. Fumio Okano, a well-known pioneer and innovator of three-dimensional (3D) displays, passed away on 26 November 2013 in Kanagawa, Japan, at the age of 61. Okano joined Japan Broadcasting Corporation (NHK) in Tokyo in 1978. In 1981, he began researching high-definition television (HDTV) cameras, HDTV systems, ultrahigh-definition television systems, and 3D televisions at NHK Science and Technology Research Laboratories. His publications have been frequently cited by other researchers. Okano served eight years as chair of the annual SPIE conference on ThreeDimensional Imaging, Visualization, and Display and another four years as co-chair. Okano's leadership in this field will be greatly missed and he will be remembered for his enduring contributions and innovations in the field of 3D displays. This paper is a summary of the career of Fumio Okano, as well as a tribute to that career and its lasting legacy.
\end{abstract}

Keywords: Fumio Okano, High-definition television system, Super Hi-Vision, Ultrahigh-definition television system, 3D television system

\section{BEGINNINGS AND EDUCATION}

Fumio Okano was born on August 15, 1952, in Ibaraki, Japan. He received B.S.(1976), M.S.(1978), and Ph.D.(1996) degrees in electrical engineering from Tohoku University, Sendai, Japan. His Ph.D. thesis was entitled "Research on Architectures for High-definition Television Image Capture Systems.”

Okano joined Japan Broadcasting Corporation (NHK) in 1978. From 1978 to 1980, he calibrated and configured cameras and monitors for a broadcast station as a video engineer. Programs produced at the station were viewed by a very large number of people, so the video used in them needed to be of very high quality. Okano had an uncompromising attitude toward image quality, reflecting his experience as a video engineer. This attitude played a key role in his research efforts over the subsequent years. In the following sections, I will summarize the main contributions of Fumio Okano.

\section{HIGH-DEFINITION TELEVISION SYSTEM}

In 1981, Okano was transferred to the NHK Science and Technology Research Laboratories (STRL), where he researched high-definition television (HDTV) cameras and HDTV systems. ${ }^{3-5}$ All of the devices comprising an HDTV system, from those for image capture to those for display, needed to be developed. In particular, image capture devices needed high performance with enough flexibility to handle the various applications and image processing tasks envisioned. Okano made five important contributions to increasing the performance of HDTV cameras: an auto-beamfocus method, registration compensation, focus-aid signals, highly sensitive handheld cameras, and a pixel-offset method.

Maintaining good beam focus is an important factor in obtaining high resolution images from an imaging tube. Okano analyzed the effects on the output signal, of small signals superimposed on the deflection waveform of the imaging tube. He found that the effect on the output signal clearly depended on the beam focus state. He used this finding to devise a method for maintaining good beam focus. This simplified the work of tuning cameras and improved camera performance.

Some color cameras that use imaging tubes separate the incoming light into red, green, and blue components before image capture because doing this provides higher resolution. A television signal is then generated by combining the signals from these three components. However, any offset in their positions causes problems such as colored outlines in the captured image or a loss of resolution in the luminance signal. Okano developed a method for avoiding problems: the relative offsets of each color image are computed using cross-correlation functions between the red, green, and blue images, and compensation is made for any offsets.

*arai.j-gy@nhk.or.jp

Three-Dimensional Imaging, Visualization, and Display 2014, edited by Bahram Javidi, Jung-Young Son,

Osamu Matoba, Manuel Martínez-Corral, Adrian Stern, Proc. of SPIE Vol. 9117, 91170K

(C) 2014 SPIE · CCC code: 0277-786X/14/\$18 · doi: 10.1117/12.2058117 
As camera resolution increases, focusing must be done more accurately. Cameras are equipped with viewfinders that are used for focusing. Small viewfinders are used for compact cameras, but small view finders have lower resolution, which makes it difficult to focus accurately. To compensate for this, Okano developed a method that visually enhances edges in the image by causing them to flicker. This focus-aid signal makes focusing easier.

Okano used these three technologies (auto-beam focus, registration support, and focus-aid signal) to develop a hand-held HDTV camera. The camera incorporated three high-gain avalanche rushing photoconductor (HARP) image sensors, which are extremely light-sensitive. This camera was used in coverage of the Seoul Olympics.

Okano also prototyped an HDTV camera using 2/3 inch CCDs developed for high-picture-quality National Television System Committee (NTSC) system cameras. This camera captures the green signal, by using two CCDs with relative positions offset by half a pixel in the horizontal direction. The prototype Hi-Vision camera was able to capture images with resolution of over 900 TV lines. This showed that HDTV camera configurations using image sensors with fewer pixels were possible.

Okano's R\&D showed that the new Hi-Vision television system had applications beyond broadcasting, including industries such as film, print, and medicine.

\section{SUPER HI-VISION SYSTEM}

The Super Hi-Vision (8K/SHV) system ("ultrahighdefinition television system" in standardization terminology) is attracting much attention as the nextgeneration broadcasting system. Okano began development of SHV at NHK., ${ }^{6,7}$ HV has four times the resolution of HDTV in both the horizontal and vertical directions and is seen as the ultimate 2D video system. In deciding the specifications for Super Hi-Vision, Okano conducted many evaluation tests and theoretical studies. In the initial stages, he prototyped a Super Hi-Vision camera using the pixeloffset method, which uses two image sensors to capture the green signal and one each for the blue and red signals. This camera used the technique he cultivated when developing HDTV cameras. The Super Hi-Vision system was exhibited at the 2005 World Exposition held in Aichi Prefecture. Programs were presented on a 600-inch screen over six months starting in March 2005 and were enjoyed by 1.56 million visitors. The Kyushu National Museum, which opened in October 2005, is equipped with a permanent SHV theater (350-inch screen). Super HiVision was subsequently introduced to many people through events such as the National Association of Broadcasters (NAB) show, the International Broadcasting Convention (IBC), and public viewings of the 2012 Olympics in London.

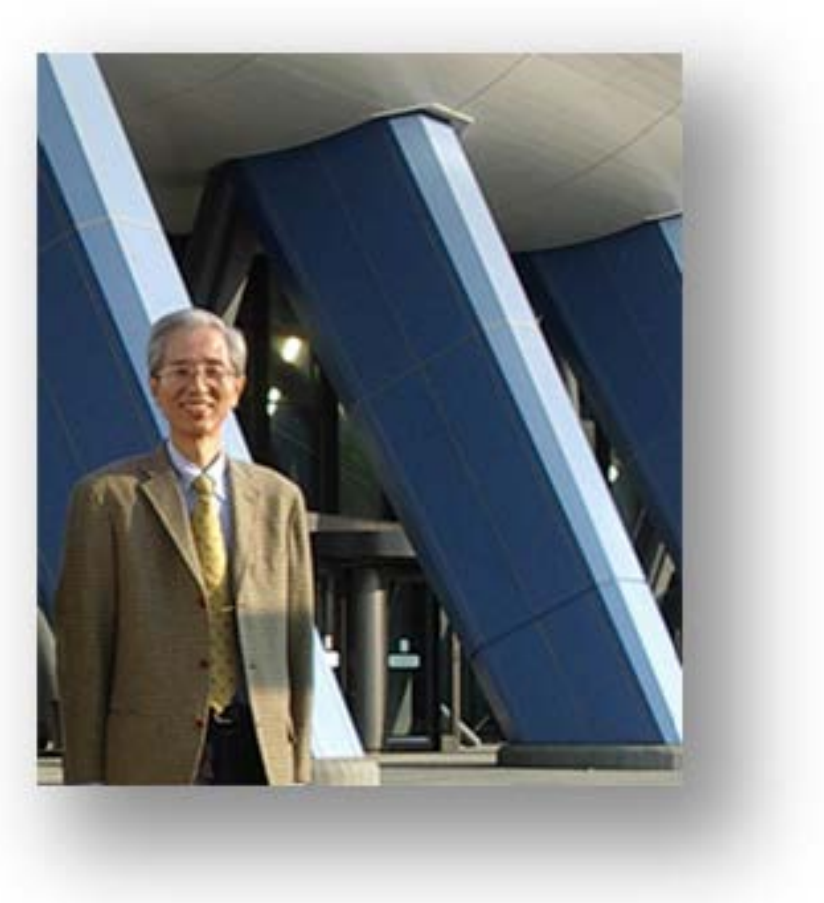

Figure 1. Photograph of Fumio Okano taken in 2004 at the Kyushu National Museum under construction.

\section{THREE DIMENSIONAL TELEVISION SYSTEM}

Okano’s enthusiasm for R\&D on new video systems did not stop with Super Hi-Vision, the ultimate 2D video system. He also had a passion for developing 3D video systems and left an important legacy in that field as well. ${ }^{1,2}$ 8-26

With respect to stereoscopic images, he was a leader in the study of such issues as the effects of stereoscopic viewing on visual function, excessive compression of 3D images in the depth direction, and the phenomenon of 3D images appearing unnaturally small. He also developed a method for converting imagery captured by the Kaguya lunar orbiter 
(also known as the Selenological and Engineering Explorer, or SELENE) into stereoscopic video. Kaguya captured motion video as it moved in a direction perpendicular to the screen. Images with a pseudo-horizontal parallax were created y rotating the captured images 90 degrees and combining two images taken at different times. The 3D images of the moon captured in this way were exhibited at NAB in 2009 and were very popular. Okano had many such ideas that were technically sound. His idea for converting the video captured by Kaguya into stereoscopic images exemplifies his being an excellent "ideas man".

Okano also conducted R\&D in the field of holography for application to building 3D television systems. It is possible to display moving 3D images by displaying interference patterns on an LCD panel. It is possible to generate high-order diffraction images by displaying interference patterns on an LCD panel, and Okano led development on equipment that expanded the range of where 3D images can be viewed. He also led the development of methods for avoiding the use of coherent light in image capture, by using information obtained with integral photography (IP) image capture equipment to generate interference patterns computationally.

Okano also left a legacy in the field of IP, which was proposed by Lippmann in 1908 as a 3D photography technique not requiring glasses for viewing. After Lippmann's proposal, various theoretical studies and attempts to improve image quality were made, but little progress was made on research applying IP to a television system. Since NHK is a broadcasting corporation, Okano led the R\&D on IP from its initial stages toward building a 3D television system. One requirement for such a system is to display motion 3D images in real time. In 1997, Okano showed that motion 3D images can be both captured and displayed in real time using a Hi-Vision camera, liquid crystal display (LCD), and lens array. However, at that time, the problem of creating pseudoscopic images, which are reversed in the depth direction relative to the subject, had not been solved yet. In 1999, in order to avoid the pseudoscopic image problem, he built prototype equipment using a gradient-index lens array. This made it possible to display 3D images that were correct in the depth direction in real time. This was a major advance in the development of an IP television system. Later, IP capture and display equipment was prototyped using 2000 scan lines and SHV video systems, improving the image quality.

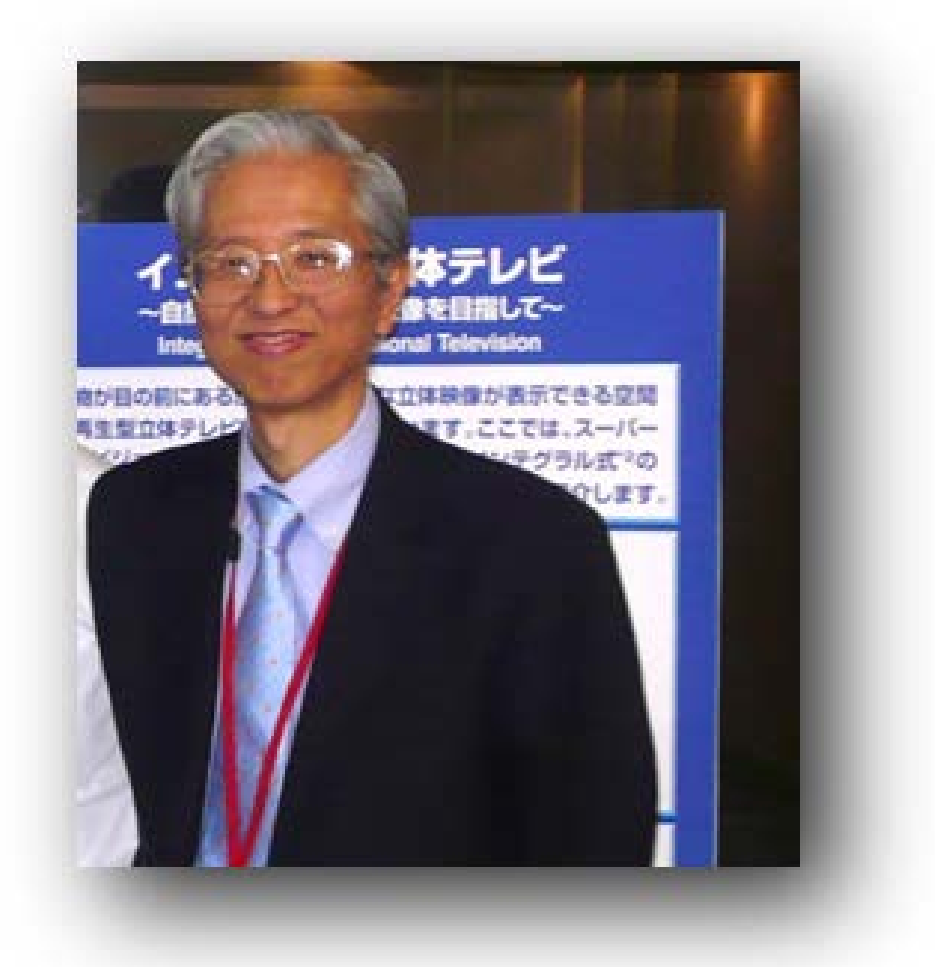

Figure 2. Photograph of Fumio Okano taken in 2008 at the NHK STRL Open House.

Developing such 3D imaging technologies, from capture to display, requires knowledge and experience that is both broad and deep. Okano had both the knowledge and experience required. He was able to utilize his experience as a video engineer and his experience in developing HDTV and Super Hi-Vision technology to make such great progress in the field of 3D video.

\section{CLOSING REMARKS}

The Hi-Vision technology that Okano worked on is now enjoyed by people around the world. The video parameters for Super Hi-Vision are being standardized by the International Telecommunication Union-Radiocommunication Sector (ITU-R) and the Society of Motion Picture and Television Engineers (SMPTE), and practical implementation is not far away. Okano also made great contributions to the application of 3D imaging technologies to television systems, enabling major advances in 3D television systems. 
In 2009, Okano moved most of his activity to NHK Engineering Systems, Inc., where he worked in management while vigorously pursuing research. He was still hard at work when he passed away in November, 2013.

Okano's leadership in these various efforts will be greatly missed. He will be remembered for his enduring contributions and innovations in the field of television technology.

Okano leaves behind a loving family - his wife, Hiromi, and two children. He will be deeply missed by all of his family, friends, and colleagues.

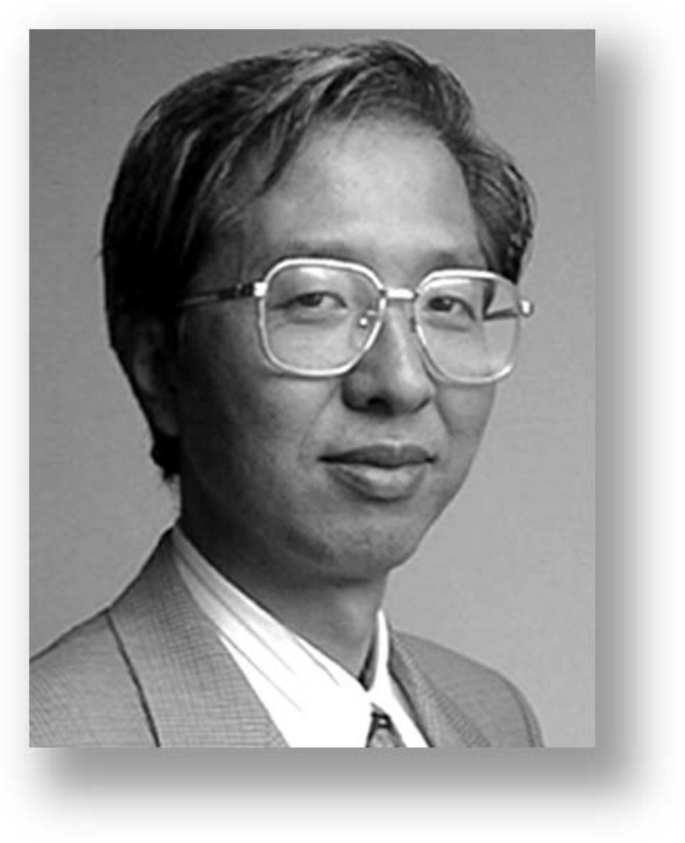

\section{ACKNOWLEDGEMENTS}

Fumio Okano's wife, Hiromi, furnished many photos of Fumio as well as remarks on the occasion of his funeral (see APPENDIX B). I also would like to thank Masaru Kanazawa for providing me with photos.

\section{APPENDIX A}

\section{Books}

[1] B. Javidi and F. Okano, Eds., [Three-Dimensional Television, Video, and Display Technologies], Springer-Verlag, Berlin, Germany (2002).

[2] B. Javidi, F. Okano, and J-Y. Son, Eds., [Three-Dimensional Imaging, Visualization, and Display], Springer-Verlag, Berlin, Germany (2010).

\section{Papers}

[3] F. Okano, J. Kumada, and K. Tanioka, “The HARP High-Sensitivity Handheld HDTV Camera,” SMPTE Journal 99(8), 612-619 (1990).

[4] F. Okano, Y. Fujita, K. Mitani, K. Kawashiri, and T. Toma, "The Dual Green Pickup Experiment for a Compact HDTV Color Camera with Three -2/3inch CCDs,” IEEE Transactions on Broadcasting 37(1), 17-22 (1991).

[5] F. Okano, J. Kumada, and N. Egami, "An HDTV High Performance HARP Camera," IEEE Transactions on Broadcasting 38(1), 12-18 (1992).

[6] M. Sugawara, M. Kanazawa, K. Mitani, H. Shimamoto, T. Yamashita, and F. Okano, "Ultrahigh-Definition Video System with 4000 Scanning Lines,” SMPTE Motion Imaging Journal 112(10\&11), 339-346 (2003).

[7] M. Kanazawa, K. Hamada, I. Kondoh, F. Okano, Y. Haino, M. Sato, and K. Doi, "An ultrahigh-definition display using the pixel-offset method,” Journal of the Society for Information Display 12(1), 93-103 (2004).

[8] M. Emoto, T. Niida, and F. Okano, "Repeated vergence adaptation causes the decline of visual functions in watching stereoscopic television,” J. Display Technology 1(2), 328-340 (2005).

[9] H. Yamanoue, M. Okui, and F. Okano, "Geometrical Analysis of Puppet Theater and Cardboard Effects in Stereoscopic HDTV Images,” IEEE Trans. Circuits and Systems for Video Technology 16(6), 744-752 (2006).

[10] M. Miura, J. Arai, J. Yamazaki, H. Sasaki, M. Okui, S. Sobue, and F. Okano, "Conversion method from moving pictures captured by high-definition television camera on Kaguya (SLENE) into stereoscopic images,” J. Display Technology 6(10), 438-442 (2010). 
[11] T. Mishina, M. Okui, and F. Okano, "Viewing-zone enlargement method for sampled hologram that uses high-order diffraction,” Appl. Opt. 41(8), 1489-1499 (2002).

[12] T. Mishina, M. Okui, and F. Okano, "Generation of holograms using integral photography," Proc. SPIE 5599, 114$122(2004)$.

[13] F. Okano, H. Hoshino, J. Arai, and I. Yuyama, "Real-time pickup method for a three-dimensional image based on integral photography,” Appl. Opt. 36(7), 1598-1603 (1997).

[14] F. Okano, J. Arai, H. Hoshino, and I. Yuyama, "Three-dimensional video system based on integral photography," Opt. Eng. 38(6), 1072-1077 (1999).

[15] F. Okano, J. Arai, H. Hoshino, M. Yamada, and I. Yuyama, "Integral three-dimensional television," International Workshop on 3-D Imaging Media Technology 5, 3-4 (1999).

[16] F. Okano, J. Arai, H. Hoshino, and I. Yuyama, "Three-dimensional television system based on integral photography,” Asia-Pacific Broadcasting Union Tech. Review 482, 3-12 (1999).

[17] F. Okano and J. Arai, "Optical shifter for a three-dimensional image by use of a gradient-index lens array," Appl. Opt. 41(20), 4140-4147 (2002).

[18] F. Okano, “3-D TV without glasses,” IEEE Circuits \& Devices Magazine 19(4), 11-16 (2003).

[19] F. Okano, J. Arai, and M. Okui, "Resolution characteristics of afocal array optics," Proc. SPIE 6016, 1-9 (2005).

[20] F. Okano, J. Arai, K. Mitani, and M. Okui, "Real-Time Integral Imaging Based on Extremely High Resolution Video System,” Proc. IEEE 94(3), 490-501 (2006).

[21] F. Okano and J. Arai “Amplified optical window for three-dimensional images," Opt. Lett. 31(12), 1842-1844 (2006).

[22] F. Okano, J. Arai, and M. Kawakita, "Wave optical analysis of integral method for three-dimensional images," Opt. Lett. 32(4), 364-366(2007).

[23] F. Okano, J. Arai, and M. Okui, "Visual resolution characteristics of an afocal array optical system for threedimensional images,” Opt. Eng. 46(2), 023201.1-023201.9 (2007).

[24] F. Okano, M. Kawakita, J. Arai, H. Sasaki, T. Yamashita, M. Sato, K. Suehiro, and Y. Haino, "Three-dimensional integral television using extremely high-resolution video system with 4,000 scanning lines,” Proc. SPIE 6778, 6778051.1-677805.13 (2007).

[25] F. Okano, J. Arai, and M. Kawakita, “Analysis of incident light rays into a pupil in integral imaging,” Proc. SPIE 7329, 732907.1-732907.9 (2009).

[26] J. Arai, M. Kawakita, T. Yamashita, H. Sasaki, M. Miura, H. Hiura, M. Okui, and F. Okano, "Integral threedimensional television with video system using pixel-offset method,” Opt. Exp. 21(3), 3474-3485 (2013).

\section{Patents}

6,137,937, “Autostereoscopic image apparatus,” October 24, 2000

6,301,416, “Optical three-dimensional imaging device which uses an integral photography technique,” October 9, 2001

7,054,067, “Three-dimensional image optical system,” May 30, 2006

7,292,271, "Process and apparatus for taking slow motion picture, and process and apparatus for taking and playing slow motion picture," November 6, 2007

\section{Honors}

ABU Engineering Prize, 1999, from Asia-Pacific Broadcasting Union for development of Three-dimensional Television System Based on Integral Photography (co-winner)

IBC2003 President's Award, 2003, from International Broadcasting Convention for development of Ultrahigh Definition Video System with 4000 Scanning Lines (co-winner)

SMPTE Journal Certificate o Merit Award, 2006, from Society of Motion Picture and Television Engineers for $8 \mathrm{~K} \times 4 \mathrm{~K}$ Ultrahigh-definition Color Video Camera (co-winner)

Fellow, 2010, from IEEE for contributions to High Resolution Three-dimensional Television 


\section{APPENDIX B \\ The following are remarks from Fumio Okano's wife, Hiromi, to those who attended his funeral}

\section{In memory of my husband who was passionately devoted to development of technology}

Thank you very much for taking time out of your busy schedules to be here today.

My husband, Fumio Okano, passed away in the early hours of November 26, 2013 at the tragically young age of 61. Right up to his passing, Fumio was singularly dedicated to development of new technology. Let me extend my heartfelt gratitude and appreciation to all of you who worked with Fumio.

As an engineer, Fumio poured his efforts into HDTV, Ultra HDTV, 3D video, and many other projects in which he was involved. He used to say that "by the time a new technology gets to market, we are already well onto the next development. That is the nature of the job." He only had good things to say about his colleagues, and I know he was very content and satisfied with the work he was doing for the company.

At home, Fumio was a loving father who cared deeply for our children. He brought them up right, and again I am extremely grateful for his big-heartedness and generosity.

After he became ill, Fumio developed a great interest in astronomy and weather which he captured in remarkable photographs. His spirit of inquiry was boundless, and no doubt there were many other things he would have loved to explore if he only had time. The passing of one so young and so full of life is a tremendous loss. I only hope that somehow, from the great beyond, Fumio continues to watch over us and watch over the work of his colleagues in the years to come.

Again, with this brief note, I extend to you who shared so many wonderful memories and trod the same steep path as my husband, my sincerest gratitude and appreciation. 